\title{
Diffusion of Organisational Innovation in Saudi Arabia: The Case of the Project Management Office (PMO)
}

\begin{abstract}
Recent innovation diffusion in organisations literature suggests that innovation diffusion dimensions and characteristics are not independent of each other, rather organisational internal environment interacts with both an organisational external environment and an innovation's characteristics. The purpose of this paper is to examine the validity of the framework consisting organisational innovation dimensions and characteristics within Saudi Arabian organisations.
\end{abstract}

We test this model with survey data from a large-scale survey of 223 Saudi public and private projectbased organisations, these organisations had either adopted, or intended to adopt, the Project Management Office (PMO). To obtain a broad representation of respondents, and to minimise bias, the survey did not target any specific industry. Statistical analysis, specifically exploratory factor analysis (EFA) and confirmatory factor analysis (CFA) were conducted to ascertain the factors underlying each contruct. Structural equations modelling (SEM) was sequentially utilised to determine the factor structure of the model and to assess the relationships between model constructs.

This paper took an initiative step towards a conceptual framework for organisational innovation diffusion, represented by the Project management Office (PMO). It results revealed that perceived organisational innovation climate functions as a gate way to the organisational innovation diffusion., It also was found that technology mediate the relationships between socio-culture and organisation climate for innovation. More importantly, PMO complexity was not related to the intention to implement the PMO.

The quantitative study showed that the framework is a useful tool for studying the diffusion of organisation innovation. The model can potentially form the foundations of a framework for organisations seeking to enhance the organisational innovation diffusion that could in turn strengthen their business performance.

Keywords: diffusion of innovation, organisational innovation, Project Management Office (PMO), conceptual framework, Saudi Arabia

\section{Introduction}

To many organisations, innovation is considered a key factor for success in the current global competitive business environment. Globalisation causes challenges for organisations, and competitiveness becomes strong (Shipton, Fay, West, Patterson, \& Birdi, 2005). Innovations create 
value for organisations which improves organisational competitiveness (Walter, Shirley, \& Willie, 2003). This in turn encourages organisations to embrace innovations to remain competitive (Abdullah \& Tudor, 2003). Broadly speaking, innovation is defined as the adoption of a new product, process, marketing model, or management practice within the organisation (Oslo Manual, 2005). Therefore, a traditional management attitude is not sufficient. The need to adopt an effective advanced management system is necessary (Rice, 2003).

Saudi Arabian organisations are no exception. Saudi Arabia is worthy of study for several reasons. First, it is the world's biggest oil producer and has the fourth largest natural gas reserves in the world. Second, it holds a 25\% share of the total Arab Gross Domestic Product (GDP). Third, Saudi Arabia is the world's $25^{\text {th }}$ largest exporter/importer. Fourth, the Saudi Stock Market (SSM) has the highest market capitalisation in the Arab world. Fifth, local government has taken some steps to improve the investment climate in the country to make it more attractive to domestic and foreign businesses (Khalid, 2006). Sixth, $80 \%$ of the total labour market in the country is non-Saudi, thus the country's lack of local professionals (Jasimuddin, 2001). Despite the above facts, the country's innovation outcomes are still lagging (Al-Shohaib, Al-Kandari, \& Abdulrahim, 2009; Iqbal, 2011).

The ability of organisations to manage innovation is critical. The link between innovativeness and projects undertaken is intimate; therefore, integrated advanced project management is recommended to address challenges faced by project management in improving organisations' performance (Geraldi et al., 2008; Thiry \& Deguire, 2007). These days, many organisations plan to adopt or have already adopted the Project Management Office (PMO) in order to improve their innovativeness (Dai \& Wells, 2004). The PMO is defined as a unit or department that is formally assigned various responsibilities related to the centralised and coordinated management of those projects under its domain. The PMO's responsibilities can range from providing structure, methodologies and standards on the practice of project management within the organisation, to being actually responsible for the direct management of a project (Project Management, 2008).

Our model has been tested with a sample of 223 Saudi Arabian organisations. The first half of this paper introduces the conceptual model, traces it is origins in the literature on diffusion of organisational innovations represented by the Project Management Office (PMO), and ends with hypotheses. The second half reports on the testing of this model, including measurement scales development, survey deployment and data analysis. This followed by a discussion and conclusion section. Finally, the paper ends with a discussion of research findings, and limitations and future work.

\section{The organisational innovation PMO}

Organisational innovations are not concentrated on one physical item or technique. Organisational 
innovations pertain to the organisation itself, its business practices and overall relation to its stakeholders. The introduction of an organisational innovation through business practices involves new methods to conduct work and operations. They tend to improve the organisation's performance (Oslo Manual, 2005). According to Burgess, Shaw, and Mattos (2005), the core competency of any organisation is organisational innovations. Organisational innovation is vital for advancing other innovations within the organisation. This is because organisational innovation has a significant impact on other types of innovations. It may also relate to the enhancement of a product through the improvement of its process to achieve organisational innovation. In the same sense, organisational innovations are more related to the organisations' social systems and thus are embedded within the organisations’ management activities and procedures (Damanpour, 1991).

Hobbs et al. (2008) concur with the above: 'organisational innovation is defined as a new, non-obvious and useful set of rules, processes and structure that has found viable application in organisations'. According to Dai and Wells (2004) 'Many organisations are moving in the direction of establishing PMOs or have already done so, demonstrating a high level of management confidence in the utility of this innovation'

The PMO is such an example. The PMO is a new practice enhancing organisational project management (Aubry et al., 2010). It is also a business strategy to support innovativeness in the sense that it integrates managerial and operational mandates (Aubry, Hobbs, \& Thuillier, 2007), thus improving productivity (Dooley \& O'Sullivan, 2007). The PMO introduces changes to the organisation, ensuring its competitiveness; hence, it is an organisational innovation (Aubry et al., 2010; Hobbs, Aubry, \& Thuillier, 2008). According to Hobbs et al. (2008), an organisational innovation is defined as the adoption of a useful application which comprises new rules, processes and structure. Therefore, the PMO is an organisational innovation because it is an effort to adopt new project management practice. Organisational innovation can positively influence an organisation's internal processes and in turn significantly impact other types of innovation such as product and services (Burgess, Shaw, \& Mattos, 2005). Consequently, organisational innovation is a positive step towards future innovation (Alan, 2003).

\section{Towards a conceptual framework}

The dominant culture theory of Hofstede (2001) divides the national culture into five dimensions: 1) power distance, which means power is distributed unequally; 2) uncertainty avoidance, which means the culture's members feel threatened by uncertainty; 3) individualism means tasks prevail over relationships; 4) masculinity means gender roles are separated; and 5) long-term orientation means the degree of tradition in a specific culture and to what extent these traditions are connected to its past and future. A country which has a high power distance culture means that wealth and power distinguish its 
population and that interaction among social groups is limited. In a high uncertainty avoidance country, creative behaviour and new ideas are limited by strict rules and procedures. Low levels of masculinity or individualism mean relationships and innovative behaviour is associated with the individualism of a society. The tendency to explore new ideas comes with greater freedom to explore and express opinions (Vecchi \& Brennan, 2009). Rothwell and Wissema (1986) argued that innovations need perseverance and entrepreneurship. In a conservative society which maintains the status quo, innovations will be difficult unless specific actions are taken. Hence, a relationship exists between a country's sociocultural (SOCL) construct and organisational climate for innovation (OCI).

The ability of technology to enhance knowledge sharing among employees is paramount to increasing productivity (Alwi et al., 2002). It reduces cost and need for personal contact. Communication channels are an important domain of project management (Ahuja, Yang, \& Shankar, 2009). According to Straub et. al. (2003), Arabian cultural beliefs have a strong influence on Information Technology diffusion. This technological acculturation sees technology transfer and culture in the Arab world as being interrelated and complementary. This finding is supported by Al-Sudairy (1994) and Yavas et al. (1992), who identify the diffusion of technology in Saudi Arabia as hindered by cultural and social barriers, as well as technical problems, such as lack of expertise (AL-Turki \& Tang, 1998) and lack of infrastructure and broadband services (Al-Somali, Gholami, \& Clegg, 2009). This may be due to the fact that authoritarians in the Saudi government fear the Internet which may threaten their political existence (Al-Shohaib et al., 2009). Hence, a relationship exists between a country's technology (Tech) and organisational climate for innovation (OCI).

Several studies have indicated that organisational context influences innovativeness within an organisation. Recent innovation research has reported that success or failure is related to how a particular innovation is adopted, because organisational climate influences the innovation's characteristics (Peansupap \& Walker, 2005). In particular, organisation climate influences the diffusion of innovations within organisations (Chandler, Keller, \& Lyon, 2000; Chen and Mohamed, 2007; Dackert, Lööv, \& Mårtensson, 2004; Day, 1990; Dulaimi, Nepal, \& Park, 2005b; Nystrom, Ramamurthy, \& Wilson, 2002). Organisational climate is related to the work environment in the organisation, including the behaviour and feelings of the members. These feelings are subjective to those who influence the organisation through power-management (Denison, 1996).

Contextual factors (leaders, their attitude towards change, decision-making decentralisation) and intragroup factors (support system from management, organisational committees, employee exposure to innovation and improvement, employee diversity and satisfaction) are determinants of an innovative climate in the organisation. Management's exposure, experience and background, as well as its attitude towards change, shapes the subordinates' perception and attitude to innovation. It is important to have 
leaders whose skills involve risk-taking and calculation, as well as openness to new concepts (M. A. K. Mohamed, 2002). Creating a management culture that has higher congruency with manager perceptions and organisational readiness may be considered a more beneficial means of promoting diffusion of innovations within project management. Keeping up with changes to organisational levels and work style should not be seen as difficult. Hence, the causal link exists between organisational climate for innovation (OCI) and the PMO characteristics (e.g. relative advantage, compatibility and complexity).

Rogers (2003) posits five perceived characteristics for innovation which influence its adoption: relative advantages, compatibility, complexity, observability and trialability. However, among these five, only relative advantages, compatibility, and complexity were found the most relevant (Dillon \& Morris, 1996; Hsiu-Fen \& Gwo-Guang, 2006). These three characteristics are also more relevant to the current paper for several reasons. First, since the PMO has long-term impact, management is less concerned with observability of the PMO. Second, the PMO involves significant organisational change which is difficult to reverse. Third, relative advantages, compatibility and complexity have consistently been found to be important influences of behavioural intention (Yi, Jackson, Park, \& Probst, 2006). Hence, a relationship exists between the PMO characteristics and the intention to implement the PMO (IIPMO).

Extending the above discussion, the objective of this paper is to identify relationships between organisational innovation diffusion dimensions and characteristics. To achieve this, a conceptual model was first developed based on the established conceptual framework. As presented in figure 1, the model comprises three main elements: 1) factors influencing diffusion of innovation; 2) innovation characteristics; and 3) results. Within the element of 'factors influencing diffusion of innovation', the model proposed three constructs: a country's socio-culture (SOCL), technology (Tech), and organisational climate for innovation (OCI). Within the element of 'innovation characteristics', the model proposed three constructs: PMO relative advantages, PMO compatibility and PMO complexity. The 'results' element was represented by one construct: intention to implement the PMO (IIPMO).

As enablers, each of the six constructs within elements one and two were predicted to have a relationship with the next level. The model proposed that socio-cultural and technological have relationships with organisational climate for innovation, organisational climate for innovation has a relationship with innovation characteristics, and then innovation characteristics determine the intention to implement the PMO. All seven constructs were then operationalised so that they could be accurately measured. As a result, a set of measurement variables was developed to gauge the model constructs. 


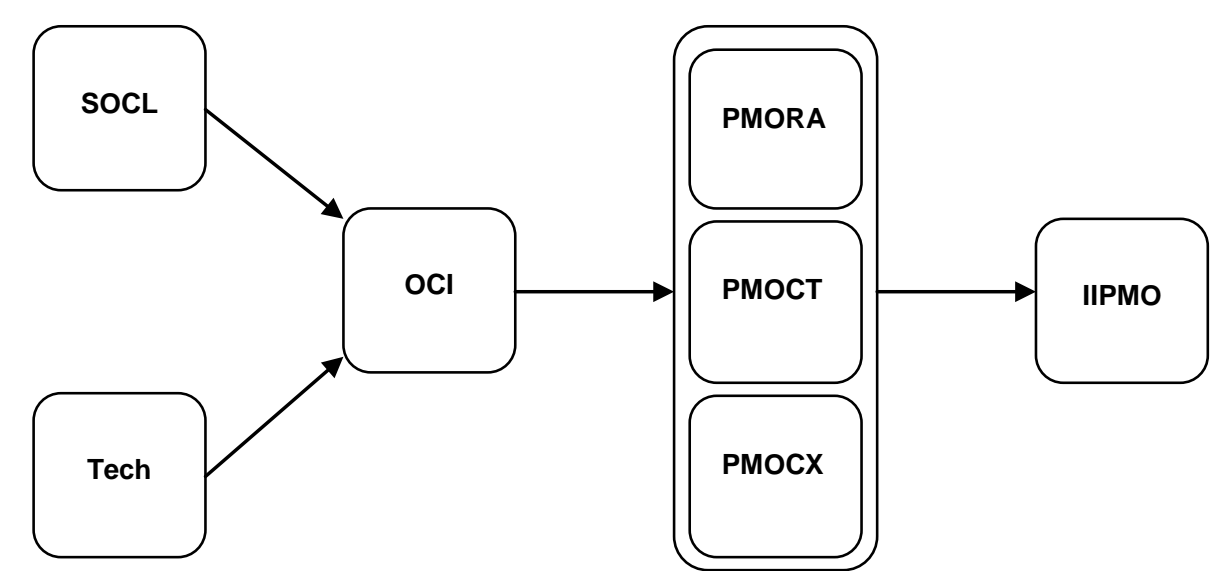

Figure 1: Conceptual model

\section{Measurement scale development and research hypotheses}

The socio-culture (SOCL) construct was operationalised using a predefined questionnaire in the field of culture and project management, as adopted by similar studies (e.g., Wang, 2001; Wang \& Liu, 2007). According to X. Wang (2001), the developed organisational culture questionnaires by Hofstede, Neuijen, Ohayv, and Sanders (1990) ask questions in such a way that the respondents would be influenced by their organisational internal environment. Wang declared that project management culture goes beyond that; therefore, these questionnaires of organisational culture are not applicable to the field of project management and culture. This was a major reason to use Wang's (2001) Project Management Culture Survey (PMCS) in the current paper. Some items of the PMCS were eliminated and others modified to make them suitable for the current research. The result is a Socio-Culture Measurement Scale with 32 items.

The organisational climate for innovation (OCI ) construct was operationalised using the support for innovation and resource supply measures developed by Scott and Bruce (1994). It was adopted by the authors after several studies in the innovation and project management environment field (Dulaimi, Nepal, \& Park, 2005a; Sarros, Cooper, \& Santora, 2008). It was selected for use in this paper because of the range of factors covering creative climate within organisations. The current paper changed some items to make them suitable for the current research. For example, 'people around here are expected to deal with problems in the same way' was changed to 'senior management are concerned with maintaining existing ways of doing work rather than changing it'. Some of the original measurement items were eliminated since they did not adapt well to the environment and organisations under the current study. Others were replaced by modified items so as to fit better with the project management environment. The result is an Organisational Climate for Innovation Measurement scale with 17 items. 
Intention to implement the PMO (IIPMO) was measured using a three-item scale employed by (Gee Woo \& Young-Gul, 2002), which was adopted by other studies (Hsiu-Fen \& Gwo-Guang, 2006). Terms such as 'needed', 'acceptable', and 'likely' were used to assess the organisation's intention to implement the PMO. These items were measured with a five-point Likert scale, ranging from 1 (very needless, very unacceptable, and very unlikely) to 5 (very needed, very acceptable, and very likely). The current paper used a 'behavioural intention' scale over an 'actual use' scale as the dependent variable for two reasons. First, according to Ajzen and Fishbein (1980, as cited in Yi et al., 2006), intention has an important affect on the behaviour to mediate the influence of other determinants on behaviour. Second, even though the current paper's target organisational innovation, the PMO, has become more popular, it is still regarded as an emerging organisational innovation.

In addition, one major task in this research was to develop an appropriate questionnaire for the constructs of technology (Tech) and the three PMO characteristics constructs, which are the PMO relative advantages (PMORA), the PMO compatibility (PMOCT) and the PMO complexity (PMOCX). No existing questionnaires were adequate to deal with the areas of project management and innovation which were specific to this paper. In developing the new scales, the current paper followed Worthington and Whittaker (2006) eight-step approach. This development process recommends that you define your construct clearly, generate a pool of items, determine the scale measurement format, have initial items reviewed by experts, consider inclusion of validation items, undertake a pilot study, evaluate the items, and then optimise the new scale length (Worthington \& Whittaker, 2006). The results are a Technology Scale with 13 items and the PMO Scale with 27 items. The PMO scale is divided into: 1) the PMO's Relative Advantages Scale with 10 items; 2) the PMO’s Compatibility Scale with seven items; and 3) the PMO’s Complexity Scale with 10 items.

\section{Research methodology}

Robert and Christopher (2001) recommend organising the questionnaire into manageable sub-sections reflecting the model constructs. The disseminated questionnaire contained five distinct sections. The current paper used one measurement scale to avoid contaminating the participants' responses (Worthington \& Whittaker, 2006). All items were measured with a five-point Likert scale, ranging from 1 (strongly disagree) to 5 (strongly agree), except for the fifth section which solicited the respondents' background information. Five-point scales were considered suitable for the multivariate analysis techniques adopted in this paper (Hair, 2006; Neuman, 2006).

The questionnaire's initial portion included a definition and description of the Project Management Office in order to minimise confusion and ensure that all respondents had a consistent concept of the PMO. The first section of the questionnaire related to the socio-cultural construct. The second section was pertinent to the technological construct. The third section pertained to the organisational climate for 
innovation construct. The fourth section of the questionnaire was divided into four parts. The first part was pertinent to the PMO relative advantages, the second part to PMO compatibility, the third to PMO complexity, and the fourth part pertained to intention to implement the PMO.

As this quantitative study aimed to test the four hypotheses of the conceptual frameworks, an adopted cross-sectional design was considered the most appropriate method to collect data. This is the most common approach for management research (Patterson et al., 2005). Once the questionnaire was developed, a pilot survey involving 10 project managers in Saudi Arabia was undertaken. The pilot survey ensured that the questions were understood by the respondents and that there were no problems with the wording of the instrument (Cavana, Delahaye, \& Sekaran, 2001).

In this paper, the unit of analysis was at the organisational level in Saudi Arabia; hence this study collected organisations' perceptions regarding the country's socio-cultural and technological factors, organisational climate for innovation, the PMO's characteristics (relative advantages, compatibility and complexity) and the intention to implement the PMO. The candidate sampling frame comprised 223 Saudi public and private project-based organisations. To avoid potential bias in the data, no more than five valid feedback questionnaires were chosen from each organisation (Thiagarajan \& Zairi, 1998). The sampling frame is Saudis who are listed with the Project Management Institute, Arabian Gulf Chapter.

\section{Data examination}

The survey was conducted in Saudi Arabia over a two-month period with the collaboration of the Project Management Institution-Arabian Gulf Chapter (PMI-AGC). Respondents consisted of a random sample of PMI-AGC members across Saudi Arabia to ensure a suitable level of experience and professionalism. E-mail was the chosen medium for the survey, together with the survey link, due to poor postal services in Saudi Arabia. Advance notice was given that a survey would be sent, followed by the survey a few days later. After two weeks a reminder was sent. After two more weeks a final reminder was sent. A total of 331 usable responses were received. The responses were considered a good representation of the opinion of the population, since at the time of the survey the majority of the respondents were well-educated and experienced: $72.6 \%$ of respondents are recognised by international project management institutions, and many respondents for this study were project managers and project engineers, accounting for $24.2 \%$ and $15.2 \%$ respectively.

In addition, 108 responses were eliminated from further analysis for two reasons. First, no more than five usable feedback questionnaires were chosen from each organisation to avoid bias in the data. Although analysis would be performed at the organisational and not the individual level (because most recent studies on innovation use organisation as the unit of analysis (Phonkaew, 2001)), multi-responses 
were retained in the data set if they were from individuals representing different sections, departments or branches of the same organisation. Second, any cases with missing data were deleted from the database. This resulted in a reduction of the sample size with no missing values for the 89 variables of the seven constructs. Based on the above rules, 223 organisations were retained for the data analysis.

It is common in such studies that researchers adhere to 'skewness' and 'kurtosis', which are considered as two important components of normality (Tabachnick \& Fidell, 2007). For a distribution to be considered normal, its skewness and kurtosis should fall between +2.00 and -2.00 (Garson, 2011). kewness of all variables, ranging from 0.01 to 1.13 , and for kurtosis values ranging from 0.04 to 1.38 , fell within the recommended range from +2.00 to -2.00 .

According to Kline (2005), cases with scores of more than three standard deviations beyond the mean may be considered outliers. In order to detect extreme deviation values in this study, the entire scores of the 89 variables for all cases were converted into standardised z-scores. Any cases with absolute value of z-scores $(|z|)$ greater that 3.29 (i.e. three standard deviations at $(p<0.01)$ were considered potential outliers (Tabachnick \& Fidell, 2007). In this study there were no indications for outlier values greater than 3.29 .

In addition, the standard deviation values of all variables in this study were not large, ranging from 0.85 to 1.30 , while the standard error values were relatively small when compared with the means, ranging from 0.05 to 0.08 . Therefore, it can be reasonably concluded that the mean value can be used as a representative score for each variable in the data, and the small values of the SE suggest that the sample used in this study was sufficiently representative of the population (Field, 2009). The paper also conducted a comparative analysis, based on the categories of organisational climates for innovation and PMO characteristics. A comparative analysis of the perceptions revealed that there were differences in their opinions on some items. These differences were addressed in a more systematic manner by employing a reliable statistics analysis procedure. A one-way Analysis of Variance (ANOVA) was performed to determine whether the differences in the opinions of these groups of respondents were statistically significant and meaningful. The results of ANOVA revealed that the data distribution was not distorted significantly by the different opinions of specific groups. Hence, the data set could be treated as a single sample.

\section{Data Analysis}

Hair (2006) recommends that values of 0.60 to 0.70 are at the lower limit of acceptability for the alpha coefficient. The values of the alpha coefficient of all seven scales, ranging from 0.836 to 0.954 , which were well above the acceptable lower limit and fell in a range that is between very satisfactory and excellent. In addition, according to Pallant (2007), a value of the corrected item-total correlation of less than 0.30 indicates that the variable is measuring something different from the construct as a whole. 
The results show that most of the variables within each construct were greater than 0.30 , with the exception of the eight variables within the SOCL construct and one within the OCI construct. These nine variables were eliminated from both constructs.

According to Pallant (2007), the Kaiser-Meyer-Olkin measure of sampling adequacy (KMO), and Bartlett's test of sphericity, are generally applied to determine the factorability of such a matrix. The results show that the values of KMO ranged from 0.689 to 0.928 , making them well above the minimum acceptable level of 0.60 (Tabachnick \& Fidell, 2007), and thus indicating sampling adequacy. Bartlett's test of sphericity statistic for each construct was large and significant at the 0.0005 level, indicating that there were adequate relationships between the variables included in the analysis. Finally, all anti-image correlation values ranged from 0.492 to 0.946 . These results confirmed the factorability of the exploratory factor analysis (EFA) conducted for each construct (Hair, 2006; Pallant, 2007).

\section{Exploratory factor analysis}

Exploratory factor analysis (EFA) was adopted for identifying the structure among the set of measurement variables for each construct in the model, and also for data reduction. The VARIMAX method for orthogonal rotation under the component factor model was chosen to give a clear separation of the factors. The 223 cases met the acceptable sample size of 100 for undertaking factor analysis, which exceeded the minimum requirement (i.e. five times as many subjects as the variables to be analysed in the construct with the largest number of variables) (Hair et al., 1998). To achieve this, a combination of the following criteria was used: 1) Latent root (eigenvalues greater than 1); 2) Cattell's scree test; and 3) percentage of variance (Hair et al., 1998).

Based on the above techniques and criteria, the EFA was performed separately for each of the seven constructs using the SPSS program. For the SOCL construct, both the eigenvalue and scree test criteria suggested four factors, which accounted for 58.9 percent of the total variance. The factor loadings of all variables were significant and well above the 0.50 threshold level without being loaded equally highly on more than one factor (i.e. cross loadings). As presented in Table 1, four factors were derived from the SOCL construct.

For the Tech construct, both the eigenvalue and scree test criteria suggested two factors, which accounted for 58.3 percent of the total variance. The factor loadings of nine variables were significant and well above the 0.50 threshold level without being loaded equally highly on more than one factor. Nevertheless, four variables were dropped due to their low factor loadings. As presented in Table 1, two factors were derived from the Tech construct. 
For the OCI construct, both the eigenvalue and the scree test criteria suggested three factors, which accounted for 61.1 percent of the total variance. The factor loadings of 14 variables were significant and above the 0.50 threshold without being loaded equally highly on more than one factor. Nevertheless, two variables were dropped due to their low factor loadings. As presented in Table 1, three factors were derived from the OCI construct.

For the PMO relative advantages construct, the initial principal component analysis presented a single component with eigenvalue exceeding one, and explained 70.7 percent of the variance. All 10 variables were significant and well above the 0.50 threshold level. No variable was deleted during the analysis for the PMORA construct. For the PMO compatibility construct, the initial principal component analysis presented a single component with eigenvalue exceeding one, and explained 67.7 percent of the variance. All seven variables were significant, all were well above the 0.50 threshold level, and no variable was deleted during the analysis for the PMOCT construct. For the PMO complexity construct, both the eigenvalue and the scree test criteria suggested two factors, which accounted for 69.5 percent of the total variance. The factor loadings of 10 variables were significant and above the 0.50 threshold level without being loaded equally highly on more than one factor. As presented in Table 1, one factors for the PMORA construct, one factor for PMOCT construct, and two factors were derived from the PMOCX construct.

For the intention to implement PMO construct, the initial principal component analysis presented a single component with eigenvalue exceeding 1 , and explained 75.7 percent of the variance. All three variables were significant, were well above the 0.50 threshold level, and no variable was deleted during the analysis for the IIPMO construct, as presented in Table 1. 
Table 1: Summary of EFA results

\begin{tabular}{|c|c|c|c|c|}
\hline Construct & $\begin{array}{l}\text { Factor(s) } \\
\text { Extracted }\end{array}$ & $\begin{array}{c}\text { Cronbach's } \\
\text { Alpha }\end{array}$ & $\begin{array}{c}\text { Cumulative } \\
\text { Variance }\end{array}$ & Factor: Description \\
\hline Socio-Culture (SOCL) & 4 & 0.858 & 58.964 & $\begin{array}{l}\text { SOCL1: Participative } \\
\text { Culture (5 variables) } \\
\text { SOCL2: Collectivist Culture } \\
\text { (5 variables) } \\
\text { SOCL3: Hierarchical } \\
\text { Culture (5 variables) } \\
\text { SOCL4: Autocratic Culture } \\
\text { (3 variables) }\end{array}$ \\
\hline Technology (Tech) & 2 & 0.845 & 58.319 & $\begin{array}{l}\text { Tech1:Availability and } \\
\text { Implementation } \\
\text { (5 variables) } \\
\text { Tech2:Research and } \\
\text { Development (4 variables) }\end{array}$ \\
\hline Organizational Climate for Innovation (OCl) & 3 & 0.870 & 61.119 & $\begin{array}{l}\text { OCI1:Managerial Support } \\
\text { Climate (5 variables) } \\
\text { OCI2:Operational Support } \\
\text { Climate (4 variables) } \\
\text { OCI3:Status-quo } \\
\text { (4 variables) }\end{array}$ \\
\hline PMO Relative Advantages (PMORA) & 1 & 0.954 & 70.719 & $\begin{array}{l}\text { PMORA: } \\
\text { Relative Advantages } \\
\text { (10 variables) }\end{array}$ \\
\hline PMO Compatibility (PMOCT) & 1 & 0.920 & 67.724 & $\begin{array}{l}\text { PMOCT: Compatibility } \\
\text { (7 variables) }\end{array}$ \\
\hline PMO Complexity (PMOCX) & 2 & 0.915 & 69.531 & $\begin{array}{l}\text { PMOCX1: } \\
\text { Relative Disadvantages } \\
\text { (7 variables) } \\
\text { PMOCX2: } \\
\text { Post-implementation } \\
\text { Disadvantages } \\
\text { (3 variables) }\end{array}$ \\
\hline Intention to implement PMO (IIPMO) & 1 & 0.836 & 75.734 & $\begin{array}{l}\text { IIPMO: Intention to } \\
\text { Implement PMO } \\
\text { (3 variables) }\end{array}$ \\
\hline
\end{tabular}




\section{Structural equation modelling}

In general, structural equation modelling (SEM) is employed primarily to determine whether a conceptual model is valid by specifying, estimating and evaluating the linear relationships among a set of variables (Shah \& Goldstein, 2006). For the purpose of this research SEM was carried out using a two-step approach. This involves, specifying and assessing the measurement model and then testing the structural model to examine the relationships between constructs. It depicts the relationships between the constructs, which can be used to determine whether the constructs are accurately measured. It specifies and assesses the model to establish the validity and unidimensionality (Gerbing \& Anderson, 1988).

In addition, these data characteristics also justified the use of the model fit indices, normed chi-square $\left(\chi^{2} / d f<3\right)$; goodness-of-fit index (GFI); Tucker-Lewis index (TLI), comparativefit index (CFI); incremental-fit index (IFI); and root mean square error of approximation (RMSEA). According to the results of a simulation conducted by Shah and Goldstein (2006), these fit indices were not found to be substantially biased under the condition of nonnormality or sample size when using the ML estimation method. For the model to be considered as having an acceptable fit, all the indices were measured against the following criteria: $\chi^{2} / d f<3.00$; GFI, IFI, TLI, and CFI > 0.90; and RMSEA < 0.08 (Hair et al., 2006).

\section{Measurement model assessment}

Confirmatory factor analysis (CFA) was employed to establish a valid measurement model prior to testing the structural model. CFA was conducted using AMOS 19. In light of these data characteristics, the maximum likelihood (ML) was considered the most appropriate method (Shah \& Goldstein, 2006). As a guide, Hair (2006) suggested that the factor loadings should be greater than 0.50. Koufteros (1999), however, argued that only significant $t$-values should suffice to demonstrate convergent validity. Hence, in addition to significant factor loadings, the reliability of the variables, which can be determined by inspecting the $R^{2}$ value, is also an indicator of convergent validity. As recommended by Bollen (1989), a variable should have an $R^{2}$ value greater than 0.50 in order to demonstrate an acceptable reliability. Discriminant validity is the extent to which a construct is truly distinct from other constructs (Hair, 2006). Thus high discriminant validity provides evidence that a construct is unique and captures some phenomena that other measures do not. According to Kline (2005), discriminant validity can be assessed by an inspection of the correlation coefficient between each pair of variables. If the value of the correlation coefficient is very high (i.e. greater than 0.850) then the variables of interest might represent the same concept and should be combined as a single variable (Tabachnick \& Fidell, 2007). 
In this paper, the measurement model was developed by integrating the individual CFA models of all the constructs into a single model. The three constructs (SOCL, Tech and OCI) within the model consisted of three layers: 1) indicators, signifying the measured variables; 2) first-order factors, signifying the factors derived from the factor analysis; and 3) second-order factors, signifying the underlying constructs. According to Edwards and Bagozzi (1998), the current model is classified as total disaggregation because each variable is an individual item, and where all the individual measured variables were included in the analysis, this type of specification potentially impacts the model's parsimony, leading to inaccurate parameter estimates or the calculation of parameters unable to converge.

Due to the above considerations, item parcelling techniques were deployed for two reasons. First, to reduce the complexity of the model, and second, to unify all the constructs into a twolayer model. This aggregation method was applied by summing, or taking, the mean of several variables that measure the same construct (Hair, 2006). According to Kline (2005), the assumption of unidimensionality must be met before conducting the item parcelling technique. The constructs unidimensionality were established in the CFA technique conducted above. In this case, item parcelling techniques were utilised for all variables in SOCL, Tech and OCI constructs to represent their respective factor. As represented in figure 2, the measurement model was simplified into a two-layer model for all constructs by integrating the individual CFA models.

As represented in table 3, the measurement model exhibited a good level of fit $\left(\chi^{2}=129.76\right.$; $d f=67 ; \chi^{2} / d f=1.93 ; \mathrm{GFI}=0.92 ; \mathrm{IFI}=0.94 ; \mathrm{TLI}=0.91$; CFI $=0.94$; and RMSEA = 0.06). All the indicators had significant loadings greater than $0.50(p<0.001)$ on their respective constructs, with the exception of three. In terms of indicator reliability, four indicators (SOCL3, Tech2, OCI2 and OCI3) had $R^{2}$ values quite lower than the recommended level of 0.50 , suggesting the potential for elimination.

However, since their factor loadings were meaningful and highly significant, they were retained in the measurement model. All of the correlation coefficients between each pair of the constructs were less than 0.850 , suggesting adequate discriminant validity. These results indicated that the measurement model possessed substantial convergent validity and unidimensionality. Moreover, since its fit indices proved to be satisfactory, the measurement model can be justifiably utilised for the subsequent structural model assessment. 


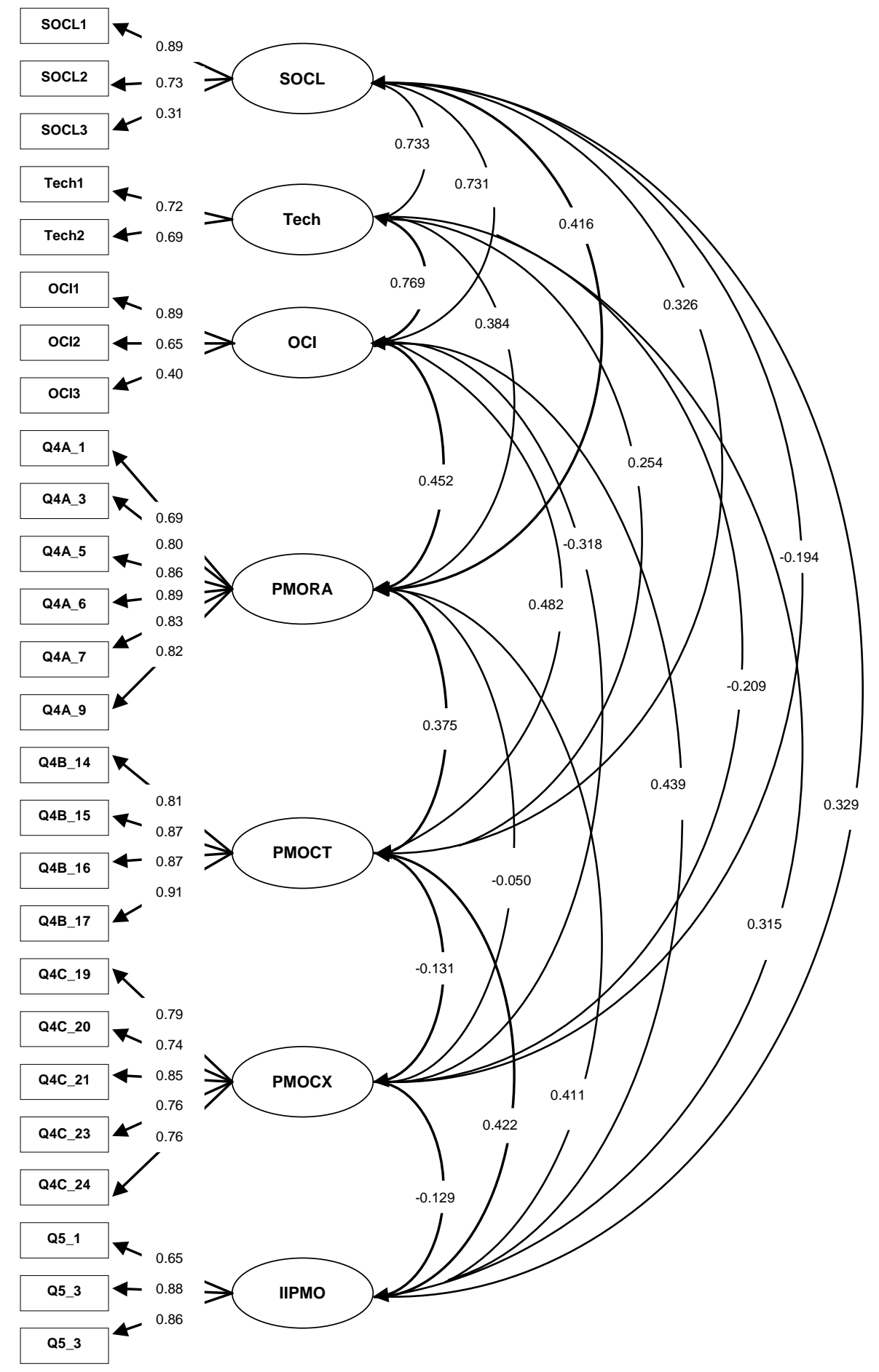

Figure 2: Final measurement model 
Table 2: Measurement model results

\begin{tabular}{|c|c|c|c|}
\hline Construct/Factors & Loading & t-value & $R^{2}$ \\
\hline \multicolumn{4}{|l|}{ Socio-Culture (SOCL) } \\
\hline SOCL1: Participative & 0.90 & f.p. & 0.81 \\
\hline SOCL2: Collectivist & 0.70 & $10.07^{\star \star *}$ & 0.50 \\
\hline SOCL3: Hierarchical & 0.31 & $4.40^{* * *}$ & 0.09 \\
\hline \multicolumn{4}{|l|}{ Technology (Tech) } \\
\hline Tech1: Availability and Implementation & 0.72 & f.p. & 0.53 \\
\hline Tech2: Research and Development & 0.69 & 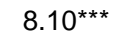 & 0.47 \\
\hline \multicolumn{4}{|l|}{ Organizational Climate for Innovation (OCl) } \\
\hline OCI1: Management support climate & 0.89 & f.p. & 0.80 \\
\hline OCl2: Operational support climate & 0.35 & $10.07^{\star \star \star}$ & 0.42 \\
\hline OCI3: Status-quo climate & 0.39 & $5.60^{\star \star \star}$ & 0.15 \\
\hline Relative Advantages (PMORA) & --- & --- & --- \\
\hline Compatibility (PMOCT) & --- & --- & --- \\
\hline Complexity (PMOCX) & --- & --- & --- \\
\hline Intention to Implement PMO (IIPMO) & --- & --- & --- \\
\hline
\end{tabular}

\section{Structural model assessment}

Once the measurement model had been validated, a structural model was examined. Initially, the model fit was assessed and the hypothesised relationships between the model constructs were tested. Non-significant relationships were removed from the conceptual structural model resulting in a refined model. The fit indices of the conceptual model were then compared with those of the refined model in order to ensure that the final model best explain the data. Figure 3 shows the results for the final structural model with standardised path coefficients. Overall, the final fit indices of the respecified model demonstrate a good level of fit: $\chi^{2}=586.96$; $d f=292 ; \chi^{2} / d f=2.00 ; \mathrm{GFI}=0.83 ; \mathrm{IFI}=0.92 ; \mathrm{TLI}=0.91 ; \mathrm{CFI}=0.92 ;$ and $\mathrm{RMSEA}=0.07$.

All the standardised path coefficients were highly significant, ranging from -0.29 to 0.72 . The results show that the SOCL construct had a very positive influence on the Tech construct $(0.72, p<0.001)$. Both SOCL $(0.38, p<0.001)$ and Tech $(0.47, p<0.001)$ were found to positively influence the OCI construct. This pattern of relationships suggests an added relationship between SOCL and Tech constructs that Tech may be an intervening construct, mediating the relationship between the SOCL and OCI constructs. 
The OCI construct had an equally positive influence on the PMORA $(0.48, p<0.001)$ and PMOCT constructs $(0.48, p<0.001)$, whereas OCI had a negative influence on PMO complexity construct. Finally, both PMORA and PMOCT had nearly equal positive influences on IIPMO: $0.30, p<0.001$ and 0.32, $p<0.001$, respectively. Finally, PMOCX construct was not related to the intention to implement PMO construct $(0.07, p<0.001)$, as hypothesised in the conceptual model presented in Figure 1.

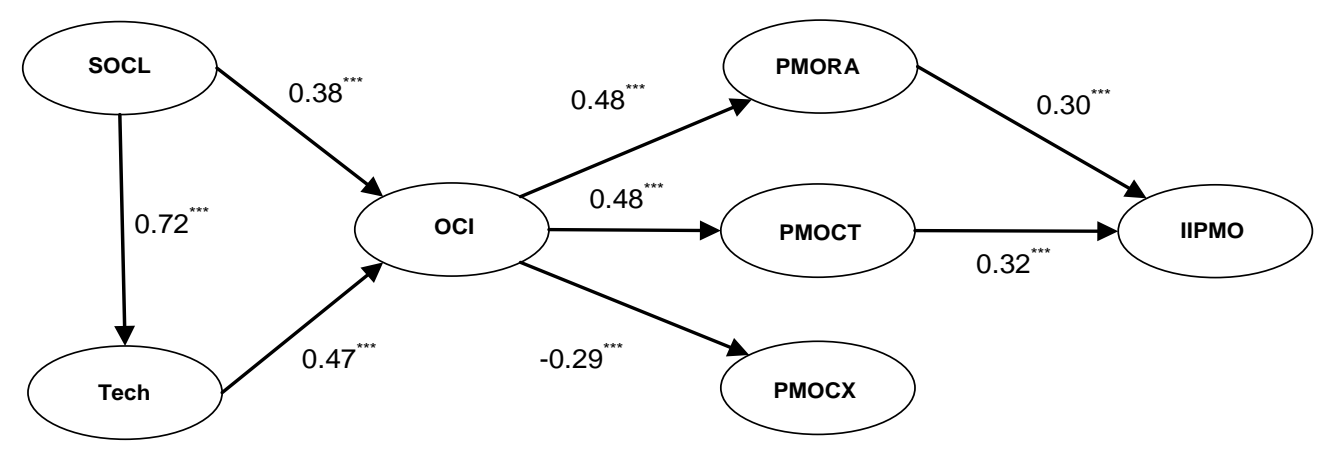

Figure 3: Final structural model with standardised path coefficients

\section{Discussion and conclusion}

The final model indicates that the country's socio-culture and technology have a direct influence on organisational climate for innovation, and both have a positive and statistically significant correlation. These results are in line with Al-Khatib et al. (2008), Bjerke and AlMeer (1993), McAlindon (2004), Rothwell and Wissema (1986) and Rouibah et al. (2009). Similarly, technology plays important roles in contributing to the creation of an organisational climate conducive to innovation. It enhances the communication among organisations' members and creates competitive advantages. However, this might be not the case in Saudi Arabia because the country's technology infrastructure is low (Al-Solbi \& Mayhew, 2005).

The process of refining the conceptual model utilising SEM revealed an additional causal link in which socio-culture has a direct influence on technology. These findings are certainly in keeping with prior research (Johannessen, 1994; Straub, Loch, \& Hill, 2001). Specifically, Straub et al. (2001) views socio-culture and technology as interrelated in Arab countries. The analysis found evidence that the moderating effect of technology on the relationship between socio-culture and organisational climate for innovation is statistically significant. Prior studies stressed the important contribution of technology in knowledge-sharing among staff members, and how managers conduct their work. Technology improves communication in the 
sense that it helps individuals compete with others (O’Dell, Grayson, \& Essaides, 1998). The literature has established the role of technology in advancing knowledge-sharing between team members, and especially among the diverse team members found in Saudi Arabia, where manpower is multicultural (Abdallah, 2007; Kivrak, Ross, \& Arslan, 2009). The dynamism and interaction of the Internet has introduced changes into Saudi Arabia's conservative society, and this development has been recognised (Sadiq, Khalid, Syed, \& Mohammed, 2007). Therefore, it can be deduced that technology is a powerful tool moderating the effect of socio-culture factors.

This result may support the creation of an open informative environment in which knowledge transfer persists between an organisation's members. It has been claimed that innovation is a combination of activities such as acquiring, disseminating, and utilising knowledge. The employees' effective use of technology is regarded as an open and flexible work environment. This leads to faster spread of innovations, because creative employees, and technology become a mechanism for encouraging innovations (Johannessen, 1994; Spanos, Prastacos, \& Poulymenakou, 2002).

The study finds that organisational climate for innovation has a direct influence on organisational innovation characteristics and the PMO in particular. In line with prior studies, the obtained results revealed that organisational climate for innovation has a positive influence on perceived relative advantages and compatibility, and a negative influence on complexity of organisational innovation (Hashem \& Tann, 2007; Hsiu-Fen \& Gwo-Guang, 2006). It seems that compatibility plays an important role in the organisation's decision to adopt a particular innovation, since it is the most sensitive among the three characteristics (Lowry, 2002).

PMO relative advantages and PMO compatibility have positive and statistically significant relationships with the intention to implement the PMO. In contrast, PMO complexity has no influence or predicting power on the intention to implement. Hence, the proposed causal link in the conceptual model between PMO complexity and the intention to implement the PMO was not supported, and it was subsequently removed. The results of the present study are consistent with Lowry's (2002) suggestion that an innovation's perceived advantage and compatibility are most significant and its complexity is less so. This supports the above finding that an organisational innovation's perceived relative advantages and compatibility are interrelated and related to the organisation's intention to implement (Dorsher et al., 2010; Hashem \& Tann, 2007; Lowry, 2002).

The above results and discussion lead to a twofold approach. First, diffusion of innovation is 
sensitive to variation of organisational climate. Therefore, modifying the internal work environment to provide a strong conducive climate for innovation is necessary. In addition, innovations within projects are not solely technical. They can be a combination of acquiring knowledge from project management practitioners and then utilising this knowledge in an environment that is conducive to diffusion of innovations, in which new ideas can be quickly implemented. Second, technology has become an important means for knowledge-sharing. Technology availability is crucial for organisations to become open to innovate, create ideas and enhance communication. Consequently, organisations that are steeped in innovative behaviour would have less resistance to change. The utilisation of technology and organisational climate for innovation could alleviate the stifling effect of Saudi Arabia's conservative culture.

\section{Implications for managerial practices}

There are several important implications from this research for Saudi Arabian organisations. The study findings suggest that the characteristics of Saudi Arabia's socio-culture imply that organisations must be deeply committed to improving the environment of creativity. Effective use of information technology is necessary to acquire and share innovative ideas. The effective use of IT to disseminate information between team members increases their ability to share knowledge and foster innovation (Peter \& Vincent, 2008). This in turn helps overcome resistance to change and increase innovation diffusion. Yitmen (2007) stressed the importance of members acquiring knowledge through IT utilisation, as it is a precondition for organisation innovativeness.

However, the understanding of organisational external factors does not necessarily lead to high levels of innovativeness, unless it is backed up by an appropriate organisational climate. The results of this study indicate that the work environment in the form of organisational climate for innovation is important for innovation. Bates and Khasawneh (2005) suggested that it is essential for organisations wishing to maximising their members' innovative behaviour to evaluate their climate to determine what changes may be needed to facilitate the innovation diffusion process.

A major part of the work in organisations is carried out by projects to achieve the organisation goals. Organisational changes should also be pursued to achieve common ground in matching goals to needs through an appropriate climate for project team members. The results of this study can be used to make project management more effective. This study offers new knowledge of how diffusion of innovation, and the PMO diffusion in particular, relate to 
different organisational contextual conditions. The successful projects are led by individuals who possess not only a blend of technical and management knowledge, but also leadership skills. Saudi organisations should inspire a new generation of project leaders whose attitudes are compatible with the motivation of the project team.

Another issue to consider when adopting an innovation is the dynamism of innovation characteristics. It has been found that relative advantages and compatibility are the most important characteristics for organisational innovations and the PMO in particular. Therefore, it's essential for organisations to take into consideration the innovation types in order for diffusion to be successful. For example, advantage and compatibility positively affect the intention to implement the PMO, whereas its complexity has a limited role. Characteristics supporting the implementation of an organisational innovation may differ from characteristics supporting a non-organisational innovation. Similarly, an advantage of an organisational innovation is that it can be imitated; however, its implementation by other organisations is difficult because every organisation has its own characteristics (Miia, Nicole, Karlos, Jaakko, \& Ali, 2006). Therefore, one approach to increasing adoption success is for the organisation to customise the innovation to fit internal conditions in which some practices need to be modified (Bodas Freitas, 2008; Koskela \& Vrijhoef, 2000).

\section{Strengths, Limitations and Future Research Directions}

The main strengths of this study are its derivation, wherein the developed framework was based on a diverse set of dimensions and characteristics from previous conceptual and empirical research. The applied operationalised measurements for the Technology and PMO characteristics constructs used in this study are new to the literature and were developed through an extensive process of literature review and questionnaire pilot study. Moreover, the framework is generalised across different industries, organisations types, and sizes. It also includes multiple levels of participants (such as general manager, project manager, supervisor, project engineer and project staff), providing confidence that bias might not exist.

The study of the same innovation (such as the PMO) in several industries within the same country (Saudi Arabia) has a benefit. Organisations in different industries can benefit from another's prior implementation of the same innovation. The effect of differences in organisational climate on innovation diffusion and innovation characteristics could give insight to the most critical components that influence the diffusion process. Future research may adopt the developed model to conduct a comparative analysis of other countries operating in similar conditions, especially in the Arab and Muslim world, to see if a comparable result can be achieved. 
The research findings reported herein should be interpreted in light of limitations. This study was limited to only one country: Saudi Arabia. Caution should therefore be taken when applying the same study to other countries. Although all measurement items were unambiguous through the questionnaire pilot study, the researcher had no control over the participants' interpretation and perception, which may or may not reflect actual situations. This is a limitation faced by all researchers who employ a questionnaire survey method (Chen, 2007).

The model has another limitation in the sense that all factors were treated as indicators representing latent constructs. In other words, the model portrays only relationships between broad organisational innovation diffusion perspective, thus offering no information as to which specific factors should receive higher priority. Therefore, a further study may be required to evaluate the interrelationships between the existing constructs at the factors level, ultimately, to develop and confirm pathways that explain the relationships among factors underpinning the empirical model. 


\section{References}

Abdullah, A.-B., \& Tudor, R. (2003). Creative team climate in an international accounting office: an exploratory study in Saudi Arabia. Managerial Auditing Journal, 18(1), 718.

Ahuja, V., Yang, J., \& Shankar, R. (2009). Study of ICT adoption for building project management in the Indian construction industry. Automation in Construction, 18(4), 415-423.

Al-Sedairy, S. T. (1994). Management of conflict : Public-sector construction in Saudi Arabia. International Journal of Project Management, 12(3), 143-151.

Al-Shohaib, K., Al-Kandari, A. A. J., \& Abdulrahim, M. A. (2009). Internet adoption by Saudi public relations professionals. Journal of Communication Management, 13(1), 21-21.

Al-Somali, S. A., Gholami, R., \& Clegg, B. (2009). An investigation into the acceptance of online banking in Saudi Arabia. 29(2), 130-141.

AL-Turki, S., \& Tang, K. (1998). Information Technology Environment In Saudi Arabia: A review. Paper presented at the Discussion Papers in Management and Organization Studies, University of Leicester.

Alan, A. B. (2003). Determinants of adoption for organisational innovations approaching saturation. European Journal of Innovation Management, 6(3), 150-158.

Aubry, M., Hobbs, B., \& Thuillier, D. (2007). A new framework for understanding organisational project management through the PMO. International Journal of Project Management, 25(4), 328-336.

Aubry, M., Müller, R., Hobbs, B., Blomquist, T., Samhällsvetenskapliga, f., Umeå, u., \& Handelshögskolan vid Umeå, u. (2010). Project management offices in transition. International Journal of Project Management, 28(8), 766-778.

Alwi, S., Hampson, K.D., \& Mohamed, S.A. (2002) Non value-adding activities: A comparative study of Indonesian and Australian construction projects. In 10th of the International Group of Lean Construction Conference, 6-8 August 2002, Gramado, Brazil.

Bagozzi, R. P., \& Youjae, Y. (1988). On the Evaluation of Structural Equation Models. Academy of Marketing Science. Journal, 16(1), 74.

Bollen, K. A. (1989). Structural equations with latent variables. New York: Wiley.

Burgess, T. F., Shaw, N. E., \& Mattos, C. d. (2005). Organisational self-assessment and the adoption of managerial innovations. International Journal of Productivity and Performance Management, 54(2), 98-112.

Byrne, B. M. (2001). Structural equation modeling with AMOS: basic concepts, applications, and programming. Mahwah, N.J: Lawrence Erlbaum Associates. 
Cavana, R. Y., Delahaye, B. L., \& Sekaran, U. (2001). Applied business research: qualitative and quantitative methods. Milton, Qld: John Wiley \& Sons Australia.

Chandler, G. N., Keller, C., \& Lyon, D. W. (2000). Unraveling the Determinants and Consequences of an Inn ovation-Supportive Organizational Culture.

Entrepreneurship: Theory and Practice, 25(1), 59.

Chen, L. (2007). Linking Knowledge Management to Organisational Business Performance in Construction. Griffith University.

Chen, L. and Mohamed, S. (2008) Contribution of knowledge management activities to organisational business performance, Journal of Engineering, Design and Technology, 6(3), $269-285$.

Churchill, G. A. (1979). A Paradigm for Developing Better Measures of Marketing Constructs. Journal of Marketing Research, 16(1), 64-73.

Dackert, I., Lööv, L.-å., \& Mårtensson, M. (2004). Leadership and Climate for Innovation in Teams. [Journal Article]. Economic And Industrial Democracy, 25(2), 301-318.

Dai, C. X., \& Wells, W. G. (2004). An exploration of project management office features and their relationship to project performance. International Journal of Project Management, 22(7), 523-532.

Damanpour, F. (1991). Organizational Innovation: A Meta-Analysis of Effects of Determinants and Moderators. The Academy of Management Journal, 34(3), 555-590.

Day, G. S. (1990). Market driven strategy: Processes for creating value. New York.

Denison, D. R. (1996). What is the difference between organizational culture and organizational climate? a native's point of view on a decade of paradigm wars. Academy of Management Review, 21(3), 619-654.

Dillon, A., \& Morris, M. G. (1996). User acceptance of information technology: Theories and models. Annual review of information science and technology, 31(Journal Article), 332.

Dooley, L., \& O'Sullivan, D. (2007). Managing within distributed innovation networks. International Journal of Innovation Management, 11(3), 397-416.

Dulaimi, M. F., Nepal, M. P., \& Park, M. (2005a). A hierarchical structural model of assessing innovation and project performance. Construction Management and Economics, 23(6), 565-577.

Dulaimi, M. F., Nepal, M. P., \& Park, M. (2005b). A hierarchical structural model of assessing innovation and project performance. Construction Management and Economics, 23(6), 565 - 577.

Edwards, J. R., \& Bagozzi, R. P. (1998). A General Approach for Representing Constructs in Organizational Research. Organizational Research Methods, 1(1), 45-87.

Fernie, S., Leiringer, R., \& Thorpe, T. (2006). Change in construction: a critical perspective. Building Research \& Information, 34(2), 91-103. 
Field, A. P. (2009). Discovering statistics using SPSS. Los Angeles: SAGE.

Garson, D. (2011). PA765: Testing of Assumptions, from http://faculty.chass.ncsu.edu/garson/PA765/assumpt.htm

Gee Woo, B., \& Young-Gul, K. (2002). Breaking the myths of rewards: An exploratory study of attitudes about knowledge sharing. Information Resources Management Journal, 15(2), 14.

Geraldi, J. G., Rodney Turner, J., Maylor, H., Söderholm, A., Hobday, M., Brady, T., \& Mittuniversitetet. (2008). Innovation in project management: Voices of researchers. International Journal of Project Management, 26(5), 586-589.

Gerbing, D. W., \& Anderson, J. C. (1988). An Updated Paradigm for Scale Development Incorporating Uni. JMR, Journal of Marketing Research, 25(2), 186.

Hair, J. F. (2006). Multivariate data analysis. Upper Saddle River, N.J: Pearson Prentice Hall.

Hobbs, B., Aubry, M., \& Thuillier, D. (2008). The project management office as an organisational innovation. International Journal of Project Management, 26(5), 547555.

Hofstede, G. (2001). Culture's Consequences. Sage Publications: Beverly Hills, CA.

Hofstede, G., Neuijen, B., Ohayv, D. D., \& Sanders, G. (1990). Measuring Organizational Cultures: A Qualitative and Quantitative Study Across Twenty Cases. Administrative Science Quarterly, 35(2), 286-316.

Hoyle, R. H. (1995). Structural equation modeling: concepts, issues, and applications. Thousand Oaks: Sage Publications.

Hsiu-Fen, L., \& Gwo-Guang, L. (2006). Effects of socio-technical factors on organizational intention to encourage knowledge sharing. Management Decision, 44(1), 74-88.

Hurley, A. E., Scandura, T. A., Schriesheim, C. A., Brannick, M. T., Seers, A., Vandenberg, R. J., \& Williams, L. J. (1997). Exploratory and Confirmatory Factor Analysis: Guidelines, Issues, and Alternatives. Journal of Organizational Behavior, 18(6), 667683.

Iqbal, A. (2011). Creativity and innovation in Saudi Arabia: An overview. Innovation management policy and practice, 13(3), 376-390.

Jasimuddin, S. M. (2001). Analyzing the competitive advantages of Saudi Arabia with Porter's model. The Journal of Business \& Industrial Marketing, 16(1), 59.

Khalid, A. (2006). The association between firm-specific characteristics and disclosure. Managerial Auditing Journal, 21(5), 476-496.

Kline, R. B. (2005). Principles and practice of structural equation modeling. New York: Guilford Press.

Koufteros, X. A. (1999). Testing a model of pull production: a paradigm for manufacturing research using structural equation modeling. Journal of Operations Management, 17(4), 467-488. 
Levin, G., \& Rad, P. F. (2003). The Project Management Office: A Critical Component of Organizational Success. Retrieved 5 August 2010, from http://www.nsp.ntnu.no/nordnet2003/papers/C2003 Levin Rad_paper.pdf.

Lillrank, P. (1995). The Transfer of Management Innovations from Japan. Organization Studies, 16(6), 971-989.

Lu, C.-S., Lai, K.-h., \& Cheng, T. C. E. (2007). Application of structural equation modeling to evaluate the intention of shippers to use Internet services in liner shipping. European Journal of Operational Research, 180(2), 845-867.

Mason, R. D., Lind, D. A., \& Marchal, W. G. (1998). Statistics: an introduction. Pacific Grove: Duxbury Press.

Mohamed, M. A. K. (2002). Assessing determinants of departmental innovation: An exploratory multi-level approach. Personnel Review, 31(5), 620--641.

Mohamed, S. (2003). Performance in international construction joint ventures: Modeling perspective. Journal of construction engineering and management - ASCE , 129(6), 619-626.

Mothe, C. D., Uyen, N. T. T., \& Nguyen-Van, P. (2011). Synergistic effects of organizational innovation practices and firm performance. CEPS/INSTEAD Working Paper Series.

Neuman, W. L. (2006). Social research methods: qualitative and quantitative approaches. Boston, Mass: Pearson/Allyn and Bacon.

Nystrom, P. C., Ramamurthy, K., \& Wilson, A. L. (2002). Organizational context, climate and innovativeness: adoption of imaging technology. Journal of Engineering and Technology Management, 19(3-4), 221-247.

Oslo Manual. (2005). The Measurement of Scientific and Technological Activities Oslo Manual: Guidelines for Collecting and Interpreting Innovation Data, 3rd Edition, OECD (18), 1-166..

Pallant, J. (2007). SPSS survival manual: a step by step guide to data analysis using SPSS for Windows (Version 15). Crows Nest, N.S.W: Allen \& Unwin.

Patterson, M. G., West, M. A., Shackleton, V. J., Dawson, J. F., Lawthom, R., Maitlis, S., .. . Wallace, A. M. (2005). Validating the organizational climate measure: links to managerial practices, productivity and innovation. Journal of Organizational Behavior, 26(4), 379-408.

Peansupap, V., \& Walker, D. H. T. (2005). Factors enabling information and communication technology diffusion and actual implementation in construction organisations. Electronic Journal of Information Technology in Construction, 10, 193-218.

Phonkaew, S. (2001). Propensity for Innovation Adoption: Integration of Structural Contingency and Resource Dependence Perspectives. ABAC Journal, 21(1).

Project Management, I. (2008). A guide of the project management body of knowledge: : Project Management Institute. 
Rice, G. (2003). The challenge of creativity and culture: a framework for analysis with application to Arabian Gulf firms. International Business Review, 12(4), 461-477.

Robert, F. K., \& Christopher, T. S. (2001). Toward a multi-dimensional measure of individual innovative behavior. Journal of Intellectual Capital, 2(3), 284-296.

Rogers, E. M. (2003). Diffusion of innovations. New York: Free Press.

Rothwell, R., \& Wissema, H. (1986). Technology, culture and public policy. Technovation, 4(2), 91-115.

Sarros, J. C., Cooper, B. K., \& Santora, J. C. (2008). Building a Climate for Innovation Through Transformational Leadership and Organizational Culture. Journal of Leadership \& Organizational Studies, 15(2), 145-158.

Scott, S. G., \& Bruce, R. A. (1994). Determinants of Innovative Behavior: A Path Model of Individual Innovation in the Workplace. The Academy of Management Journal, 37(3), 580-607.

Shah, R., \& Goldstein, S. M. (2006). Use of structural equation modeling in operations management research: Looking back and forward. Journal of Operations Management, 24(2), 148-169.

Shipton, H., Fay, D., West, M., Patterson, M., \& Birdi, K. (2005). Managing People to Promote Innovation. Creativity \& Innovation Management, 14(2), 118-128.

Straub, D. W., Loch, K. D., \& Hill, C. E. (2003). Transfer of information technology to the Arab world: a test of cultural influence modeling. Advanced topics in global information managemen, Idea Group Publishing, Hershey, PA, 2003.

Tabachnick, B. G., \& Fidell, L. S. (2007). Using multivariate statistics. Boston: Pearson/Allyn \& Bacon.

Thiagarajan, T., \& Zairi, M. (1998). An empirical analysis of critical factors of TQM: A proposed tool for self-assessment and benchmarking purposes. Benchmarking: An International Journal, 5(4), 291-303.

Thiry, M., \& Deguire, M. (2007). Recent developments in project-based organisations. International Journal of Project Management, 25(7), 649-658.

Vecchi, A., \& Brennan, L. (2009). A cultural perspective on innovation in international manufacturing. Research in International Business and Finance, 23(2), 181-192.

Walter, H., Shirley, A. H., \& Willie, E. H. (2003). Facilitating, accelerating, and sustaining the innovation diffusion process: An epidemic modeling approach. European Journal of Innovation Management, 6(2), 80.

Wang, X. (2001). Identification and evaluation of the key attributes of project management culture. Unpublished doctoral thesis, Victoria University of Technology, Melbourne, Australia.

Wang, X., \& Liu, L. (2007). Cultural barriers to the use of Western project management in Chinese enterprises: Some empirical evidence from Yunnan province. Project Management Journal, 38(3), 61-73. 
Worthington, R. L., \& Whittaker, T. A. (2006). Scale Development Research: A Content Analysis and Recommendations for Best Practices. The Counseling Psychologist, 34(6), 806-838.

Yavas, U., Luqmani, M., \& Quraeshi, Z. A. (1992). Facilitating the adoption of information technology in a developing country. Information \& Management, 23(2), 75-82.

Yi, M. Y., Jackson, J. D., Park, J. S., \& Probst, J. C. (2006). Understanding information technology acceptance by individual professionals: Toward an integrative view. Information \& Management, 43(3), 350-363.

Zikmund, W. G., Babin, B. J., Carr, J. C., \& Griffin, M. (2010). Business research methods. Mason, Ohio: South-Western Cengage Learning. 